CARDIOVASCULAR MEDICINE

\title{
Monocyte proinflammatory cytokine release is higher and glucocorticoid sensitivity is lower in middle aged men than in women independent of cardiovascular risk factors
}

\author{
P H Wirtz, R von Känel, N Rohleder, J E Fischer
}

Heart 2004;90:853-858. doi: 10.1136/hrt.2002.003426

See end of article for authors' affiliations

Correspondence to: Dr Joachim E Fischer, Institute of Behavioural Sciences, Swiss Federal Institute of Technology, Turnerstrasse 1, $\mathrm{CH}-8092$ Zurich, Switzerland; fischer@ifv.gess.ethz.ch

Accepted

8 September 2003

\begin{abstract}
Objective: To investigate whether stimulated monocyte cytokine release and its inhibition by glucocorticoids differs between men and women.

Design: In vitro monocyte interleukin 6 (IL-6) and tumour necrosis factor $\alpha$ (TNF $\alpha$ ) release after lipopolysaccharide stimulation were assessed with and without co-incubation with increasing doses of dexamethasone and hydrocortisone separately. Glucocorticoid sensitivity was defined as the amount of a particular glucocorticoid required to inhibit lipopolysaccharide stimulated monocyte cytokine release by $50 \%$. The established cardiovascular risk factors of age, body mass index, number of cigarettes smoked daily, low density cholesterol to high density cholesterol ratio, systolic and diastolic blood pressure, and haemoglobin Alc were used as covariates.

Setting: Aircraft manufacturing plant in southern Germany.

Patients: 269 middle aged male and 36 middle aged female employees.

Results: Release of monocyte IL-6 and TNF $\alpha$ (each $p=0.001$ ) was higher in samples from men than in those from women. Inhibition of lipopolysaccharide stimulated IL- 6 and TNF $\alpha$ release by either glucocorticoid was less pronounced in samples from men than in those from women (IL-6: dexamethasone $p=0.033$, hydrocortisone $p=0.029$; TNF $\alpha$ : dexamethasone $p<0.001$, hydrocortisone $p=0.089$ ). Conclusions: The finding suggests that proinflammatory activity of circulating monocytes is higher in men than in women independent of cardiovascular risk factors, thereby providing one explanation for the relatively greater coronary risk in men.
\end{abstract} relatively higher coronary risk due to older age and we controlled for established cardiovascular risk factors.

Regulatory processes in monocyte activation entail synthesis and release of proinflammatory cytokines as well as downregulation of cytokine release. While lipopolysaccharide is one of the most potent activators of monocytes, endogenous glucocorticoids effectively downregulate monocyte cytokine production. ${ }^{20-22}$ Following previous methods we assessed monocyte reactivity by measuring IL-6 and TNF $\alpha$ in whole blood after lipopolysaccharide stimulation. ${ }^{23}{ }^{24}$ Monocyte glucocorticoid sensitivity was calculated as the amount of dexamethasone required to suppress lipopolysaccharide stimulated TNF $\alpha$ and IL- 6 release by $50 \% .{ }^{14}{ }^{25}$

\section{MATERIALS AND METHODS}

Experimental patients

The study was part of a project conducted in an aircraft manufacturing plant in southern Germany ${ }^{26}$ and was formally approved by the institutional review board. From a total of 1760 employees, participation was offered to a representative sample of 532 men and women, who voluntarily completed a questionnaire based assessment of working conditions. Funding allowed medical examination and blood sampling of the first 325 participants (280 men, 45 women) who presented consecutively to the laboratory within the next 14 days, leaving 207 employees of the total representative sample whose biochemical measures were not assessed. Although the proportions of sex and duration of employment in years were the same in the two groups, those

\footnotetext{
Abbreviations: ELISA, enzyme linked immunosorbent assay; HDL, high density lipoprotein; $\mathrm{IC}_{50}$, concentration of dexamethasone or hydrocortisone that achieves a $50 \%$ inhibition of lipopolysaccharide stimulated cytokine release in the absence of any glucocorticoid; IL, interleukin; LDL, low density lipoprotein; MONICA, monitoring trends and determinants in cardiovascular disease; TNF $\alpha$, tumour necrosis factor $\alpha$
} 
who were not assessed were slightly younger (mean (SD) age 38.9 (12.6) $v 41.6$ (9.6) years). Exclusion criteria for the present study were self reported previous cardiac surgery, coronary angiography, and current medication with glucocorticoids, oral contraceptives, or antidiabetic drugs. This procedure left a study sample of 269 men and 36 women. Table 1 provides health factors including established cardiovascular risk factors of subjects.

\section{Experimental protocol}

Self reported medical history and health behaviour (smoking) were assessed by a 96 item questionnaire derived from the nurses' health study and the MONICA (monitoring trends and determinants in cardiovascular disease) study. ${ }^{27}{ }^{28}$ After completing the questionnaire, participants rested for 15 minutes while sitting. Thereafter, blood pressure was determined by sphygmomanometry twice within five minutes. Within two weeks, all participants were rescheduled on a work day and two hours after awakening to have a fasting blood sample collected. Assays were started within five minutes of blood collection in a cell culture facility adjacent to the blood collection room. Blood was processed by standard techniques in cooled $\left(4^{\circ} \mathrm{C}\right)$ citrate tubes for the $\mathrm{TNF} \alpha$ assay. Overnight urine collection for cortisol measurement started at $9 \mathrm{pm}$ the night before blood sampling and included the first void after awakening. ${ }^{29}$

\section{Glucocorticoid sensitivity and assay}

Monocytes are the main cytokine producing cells in lipopolysaccharide stimulated whole blood. ${ }^{30} 31$ The whole blood assay minimises postcollection artefacts arising from cell preparation and maintains the person's natural environment (that is, plasma compounds and hormone concentrations) as much as possible during in vitro assays. ${ }^{32} 33$

To assess monocyte glucocorticoid sensitivity, whole blood samples from each participant were stimulated with lipopolysaccharide and then co-incubated with dexamethasone and hydrocortisone separately in incremental doses. ${ }^{1422} 23$

The lipopolysaccharide stock solution (Escherichia coli O55:B5, no L2880, Sigma-Aldrich Chemie GmbH, Steinheim, Germany) was prepared by dissolving lipopolysaccharide in pyrogen-free sterile saline ( $\mathrm{NaCl} 0.9 \%$, Fresenius Kabi, Stans, Switzerland) to achieve a final concentration of $15 \mathrm{ng} / \mathrm{ml}$ lipopolysaccharide during the culture. Dexamethasone (no D8893, Sigma-Aldrich) and hydrocortisone (no H0396, SigmaAldrich) stock solutions were prepared to achieve equipotent final culture concentrations of $0,10^{-10}, 10^{-9}, 10^{-8}$, and $10^{-7} \mathrm{~mol} / \mathrm{l}$ for dexamethasone and $0,3 \times 10^{-9}, 3 \times 10^{-8}$, $3 \times 10^{-7}$, and $3 \times 10^{-6} \mathrm{~mol} / \mathrm{l}$ for hydrocortisone.

Nine millilitres of venous blood were collected into sterile pyrogen-free syringes containing $1 \mathrm{ml}$ of heparinised $0.9 \%$ saline solution. Heparinised whole blood $(400 \mu \mathrm{l})$ was added to $50 \mu \mathrm{l}$ of lipopolysaccharide stock solution and to $50 \mu \mathrm{l}$ of the stock solutions of the various concentrations of either dexamethasone or hydrocortisone on a 24 well cell culture plate (no 3047, Becton Dickinson, San Diego, California, USA). After a six hour incubation period at $37^{\circ} \mathrm{C}$ in $5 \% \mathrm{CO}_{2}$, plates were centrifuged for 10 minutes at $2000 \mathrm{~g}$ at $4^{\circ} \mathrm{C}$. The supernatant was collected and stored at $-80^{\circ} \mathrm{C}$ until assayed.

\section{Biochemical analyses}

Stimulated plasma concentrations of TNF $\alpha$ and IL-6 were determined by commercially available enzyme linked immunosorbent assay (ELISA) kits (BD Pharmingen, San Diego, California, USA). High sensitivity ELISAs were chosen to measure plasma concentrations of TNF $\alpha$ (Quantikine HS, R\&D Systems Europe, Abingdon, UK) and of $\mathrm{C}$ reactive protein (Immunolite, DPC Biermann GmbH, Germany; detection limit $0.1 \mathrm{mg} / \mathrm{l}$ ). LDL and HDL cholesterol, haemoglobin Alc, and urinary cortisol were determined by a commercial laboratory. To obtain a complete blood count including a differential count, blood was collected into $2.7 \mathrm{ml}$ EDTA tubes (Sarstedt, Rommelshof, Germany) and processed on a Sysmex SE-9000 cell counter (Sysmex, Norderstedt, Germany) within three hours after collection.

\section{Statistical analyses}

As an index for monocyte glucocorticoid sensitivity, we calculated the $\mathrm{IC}_{50}$ of the dose-response curve for dexamethasone or hydrocortisone inhibition of lipopolysaccharide induced cytokine release. The $\mathrm{IC}_{50}$ reflects the particular dexamethasone or hydrocortisone concentration that achieves a $50 \%$ inhibition of lipopolysaccharide stimulated cytokine release in the absence of any glucocorticoid. The $\mathrm{IC}_{50}$ is inversely related to glucocorticoid sensitivity-that is, a higher $\mathrm{IC}_{50}$ indicates lower sensitivity and a lower $\mathrm{IC}_{50}$ indicates higher sensitivity. The $\mathrm{IC}_{50}$ is calculated intraindividually by a logistic curve fit function (mean determination coefficient of $r^{2}=0.99$ ). The resulting measure is independent of the absolute number of circulating monocytes.

All calculations were done with SPSS version 10.0 (SPSS Inc, Chicago, Illinois, USA) and CurveExpert 1.3 (Daniel G Hyams, Hixson, Texas, USA) statistical software packages. All data are presented as mean (SEM). Results were considered significant at the $\mathrm{p} \leqslant 0.05$ level; all tests were two tailed. To approximate a normal distribution, $\mathrm{IC}_{50}$ values were $\log$ transformed. In case of missing data, cases were excluded listwise.

Across the two subject groups, univariate analyses of variance were calculated for lipopolysaccharide stimulated cytokine production and $\mathrm{IC}_{50}$ values. Repeated measure analyses of variance were calculated for dose-response curves

Table 1 Health factors of 305 men and women studied

\begin{tabular}{lccl}
\hline & Women $(\mathbf{n = 3 6 )}$ & Men $(\mathbf{n = 2 6 9 )}$ & p Value \\
\hline Age (years) & $42.0(1.5)$ & $41.4(0.6)$ & 0.71 \\
Body mass index $\left(\mathrm{kg} / \mathrm{m}^{2}\right)$ & $24.77(0.69)$ & $26.76(0.23)$ & 0.004 \\
LDL:HDL ratio & $2.30(0.14)$ & $3.00(0.06)$ & 0.000 \\
Tumour necrosis factor $\alpha(\mathrm{pg} / \mathrm{ml})$ & $1.89(0.14)$ & $1.98(0.10)$ & 0.74 \\
C reactive protein $(\mathrm{mg} / \mathrm{l})$ & $1.82(0.32)$ & $2.08(0.24)$ & 0.70 \\
Systolic blood pressure $(\mathrm{mm} \mathrm{Hg)}$ & $125(2.7)$ & $133(1.0)$ & 0.005 \\
Diastolic blood pressure $(\mathrm{mm} \mathrm{Hg})$ & $78.2(1.6)$ & $82.8(0.6)$ & 0.013 \\
Cigarettes/day & $4.4(1.3)$ & $5.9(0.6)$ & 0.40 \\
Haemoglobin Alc (\%) & $5.17(0.11)$ & $5.17(0.03)$ & 0.99 \\
Urinary cortisol $(\mu \mathrm{g} / \mathrm{l})$ & $38.8(4.6)$ & $43.5(2.0)$ & 0.41 \\
Monocytes $\left(\times 10^{5} / \mathrm{ml}\right)$ & $5.72(0.32)$ & $5.92(0.01)$ & 0.50 \\
\hline Values are mean (SEM). & & \\
HDL, high density lipoprotein cholesterol; LDL, low density lipoprotein cholesterol. & \\
\hline
\end{tabular}


of dexamethasone or hydrocortisone inhibition of lipopolysaccharide induced cytokine production. We applied HuynhFeldt corrections for repeated measures, which allow comparisons of cytokine release per cell. All analyses of variance were computed and are presented for the established cardiovascular risk factors of age, body mass index, number of cigarettes smoked daily, LDL:HDL ratio, systolic and diastolic blood pressure, and haemoglobin Alc as covariates throughout.

\section{RESULTS}

\section{Cardiovascular risk factors and health factors}

Men had higher body mass index, LDL:HDL ratio, and systolic and diastolic blood pressures than women (table 1). Of note, lack of a difference in overnight urinary cortisol excretion indicates that men and women had equal hypothalamic-pituitary-adrenal axis activity.

\section{Stimulation of cytokine production by lipopolysaccharide}

There were no sex differences in basal plasma $\mathrm{C}$ reactive protein and $\mathrm{TNF} \alpha$ concentrations (table 1). After controlling for the absolute monocyte count and all established cardiovascular risk factors mentioned above, the release of lipopolysaccharide stimulated $\operatorname{TNF} \alpha\left(F_{1,249}=12.2, \mathrm{p}=\right.$ $0.001, \mathrm{n}=258)$ and IL-6 release $\left(F_{1,248}=12.0, \mathrm{p}=\right.$ $0.001, \mathrm{n}=267$ ) was significantly higher in samples from men than in those from women (figs 1 and 2).

\section{Inhibition of stimulated cytokine production}

Figures 1 and 2 show inhibition curves for TNF $\alpha$ and IL-6 releases following lipopolysaccharide stimulation plotted against increasing concentrations of the two glucocorticoids dexamethasone and hydrocortisone. The curves show reduced capacities of both glucocorticoids to inhibit cytokine release in men as compared with women. When controlling for all established cardiovascular risk factors, TNF $\alpha$ inhibition was less pronounced in samples from men than in those from women with both dexamethasone $\left(F_{2.6,614.9}=6.7\right.$, $\mathrm{p}<0.001, \mathrm{n}=250)$ and hydrocortisone $\left(F_{3.1,726.5}=4.1\right.$, $\mathrm{p}=0.006, \mathrm{n}=246)$. Likewise, in cells obtained from men IL-6 inhibition was lower with dexamethasone $\left(F_{2.7,630.2}=3.2, \mathrm{p}=0.029, \mathrm{n}=240\right)$ and with hydrocortisone $\left(F_{3.7,840.7}=3.9, \mathrm{p}=0.005, \mathrm{n}=237\right)$ than in those harvested from women.

\section{Glucocorticoid sensitivity of cytokine release}

The IC 50 pattern of TNF $\alpha$ and IL-6 was similar (figs 3 and 4). With glucocorticoid inhibition, $\mathrm{IC}_{50}$ for samples from men was higher for $\mathrm{TNF} \alpha$ (dexamethasone: $F_{1,243}=20.2$, $\mathrm{p}<0.001, \mathrm{n}=252 ;$ hydrocortisone: $F_{1,245}=2.9, \mathrm{p}=$ $0.089, \mathrm{n}=254$ ) and for IL-6 (dexamethasone: $F_{1,233}=$ 4.6, $\mathrm{p}=0.033, \mathrm{n}=242 ;$ hydrocortisone: $F_{1,230}=4.9$, $\mathrm{p}=0.029, \mathrm{n}=239$ ) than for those from women (all cardiovascular risk factors accounted for). In other words, a higher amount of a particular glucocorticoid was required to suppress cytokine release from monocytes in response to the same lipopolysaccharide stimulus in men than in women. Thus, men had a lower monocyte glucocorticoid sensitivity than women.

\section{DISCUSSION}

In this study, we compared the monocyte glucocorticoid sensitivity between middle aged men and women while controlling for known risk factors for cardiovascular disease. We used an in vitro assay to measure monocyte cytokine release in response to a standardised dose of lipopolysaccharide and to assess the extent to which this cytokine release was inhibited by increasing concentrations of two glucocorticoids.

The main finding of our study is that, even when controlling for well known cardiovascular risk factors, blood samples from men required larger quantities of either dexamethasone or hydrocortisone to inhibit lipopolysaccharide stimulated release of IL- 6 and TNF $\alpha$ than did samples from women, while the cytokine release without glucocorticoid co-incubation was higher in samples from men than in those from women. The findings suggest higher proinflammatory activity in blood monocytes of men than in monocytes harvested from women. This notion becomes even stronger given that we controlled for established cardiovascular risk factors. Previous studies have shown that, on average, men have higher body mass index, higher LDL:HDL ratio, and higher systolic and diastolic blood pressures than women. ${ }^{143435}$ Therefore, to prevent confounding, cardiovascular risk factors need to be controlled for when testing for a unique sex difference in monocyte glucocorticoid sensitivity.

What may the clinical implications of our findings be and how do they fit with the literature? Our findings indicate that the proinflammatory response of monocytes to an equal

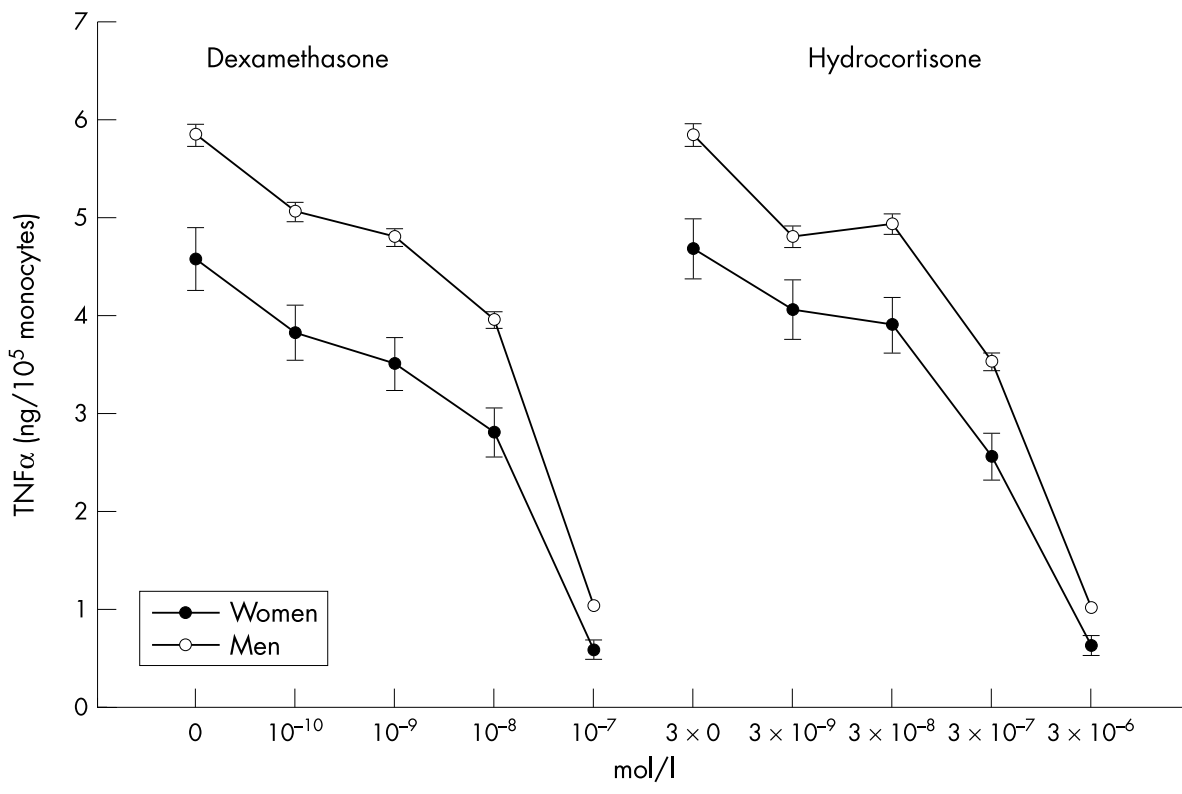

Figure 1 Curves showing the concentration of dexamethasone or hydrocortisone that achieved a $50 \%$ inhibition of lipopolysaccharide stimulated cytokine release in the absence of any glucocorticoid $\left(\mathrm{IC}_{50}\right)$. Lipopolysaccharide stimulated release of tumour necrosis factor $\alpha$ (TNF $\alpha$ ) and inhibition of TNF $\alpha$ release by glucocorticoids in blood samples from men and women (mean (SEM)). Note that the starting points of the individual $\mathrm{IC}_{50}$ curves refer to the uninhibited release of TNF $\alpha$ in response to lipopolysaccharide. Samples from men produced more TNF $\alpha$ than did those from women when stimulated with lipopolysaccharide $\left(F_{1,249}=12.2\right.$, $p=0.001$ ) and when inhibited by increasing concentrations of dexamethasone $\left(F_{2.6}, 614.9=6.7\right.$, $\mathrm{p}<0.001)$ and hydrocortisone $\left(F_{3.1,726.5}=4.1, \mathrm{p}=0.006\right)$. 


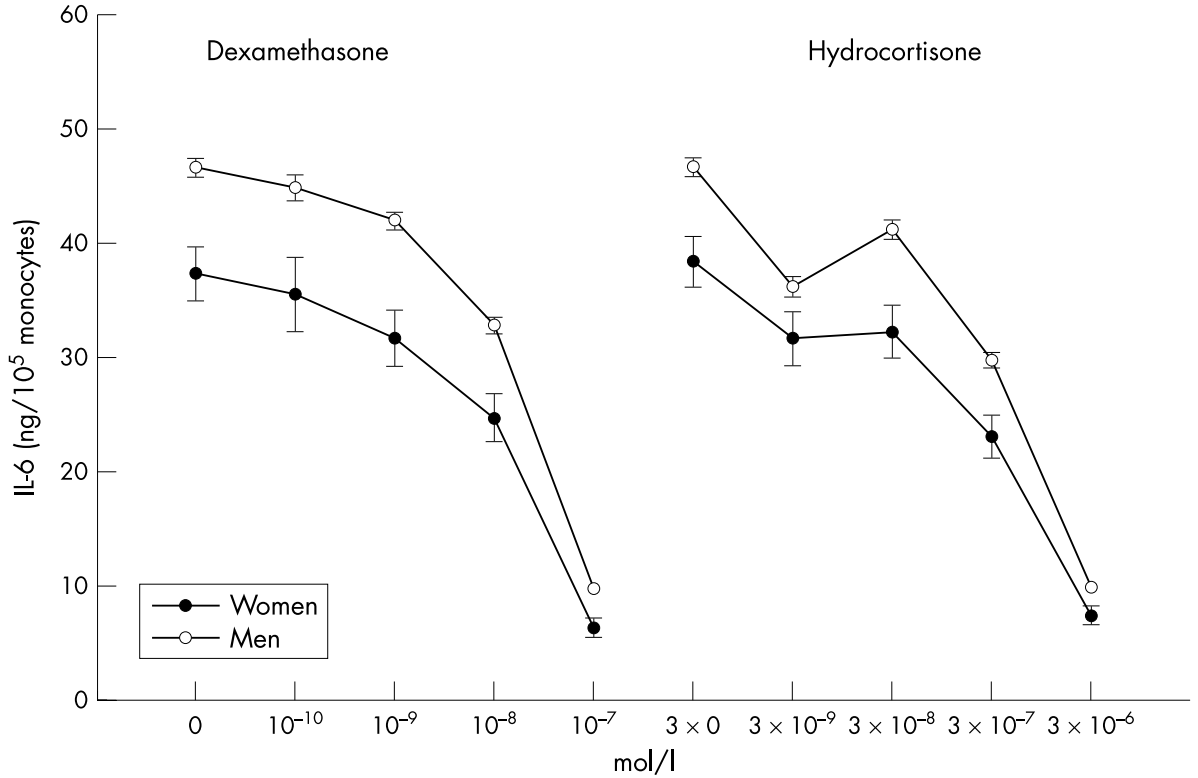

Figure 2 Lipopolysaccharide stimulated release of interleukin 6 (IL-6) and inhibition of IL- 6 release by dexamethasone in blood samples from men and women (mean (SEM)). Note that the starting points of the individual $I_{50}$ curves refer to the uninhibited release of IL- 6 in response to lipopolysaccharide. Samples from men produced more IL- 6 than did those from women when stimulated with lipopolysaccharide $\left(F_{1,248}=12.0\right.$, $\mathrm{p}=0.001$ ) and when inhibited by increasing concentrations of dexamethasone $\left(F_{2.7,630.2}=3.2\right.$, $\mathrm{p}=0.029$ ) and hydrocortisone $\left(F_{3.7,840.7}=3.9, \mathrm{p}=0.005\right)$. amount of lipopolysaccharide, such as that produced by bacteria present within an atherosclerotic lesion, is higher in men than in women. Corroborating these findings, some investigators found greater $\mathrm{TNF} \alpha$ release with lipopolysaccharide stimulation in men than in women ${ }^{36}{ }^{37}$ and with IL$6,{ }^{37}$ while others did not detect such differences. ${ }^{14}{ }^{38}$ Further driving such controversy, Rohleder and colleagues ${ }^{14}$ found lower sensitivity of monocyte IL-6 release with dexamethasone inhibition in men than in women, while Daun and colleagues $^{39}$ did not find such a sex difference in hydrocortisone regulation of lipopolysaccharide stimulated production of IL-1 $\beta$ from peripheral blood mononuclear cells. In contrast to our study, however, those studies had relatively smaller population samples that consisted mainly of young and healthy people who conceivably have a lower cardiovascular risk than our middle aged participants.

Epidemiological data support the notion that increased plasma concentrations of TNF $\alpha$ and IL- 6 increase the risk of coronary artery disease. ${ }^{10-12} 40$ Thus, differential regulation of monocyte TNF $\alpha$ and IL-6 production may provide a link between sex and the progression of atherosclerotic lesions. Our data suggest that monocytes from men not only are predisposed towards more pronounced release of TNF $\alpha$ and

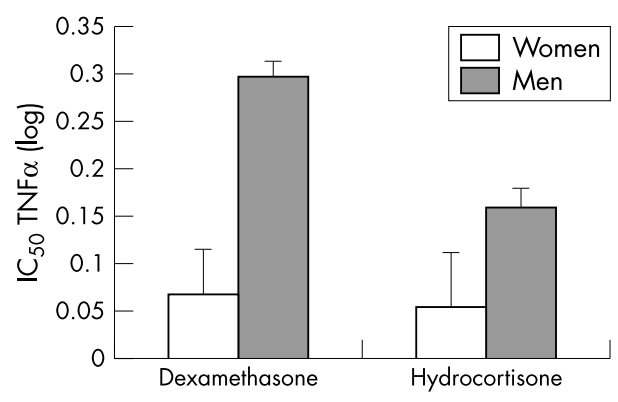

Figure 3 Glucocorticoid (dexamethasone or hydrocortisone) sensitivity of lipopolysaccharide stimulated release of TNF $\alpha$ in the blood samples from men and women. The IC $C_{50}$ is inversely related to glucocorticoid sensitivity - that is, a higher $\mathrm{IC}_{50}$ indicates lower sensitivity and vice versa. Samples from men required relatively more dexamethasone $(p<0.001)$ and hydrocortisone $(p=0.089)$ to suppress lipopolysaccharide stimulated TNF $\alpha$ release than did samples from women. In other words, monocytes of men were less sensitive to glucocorticoid suppression than monocytes from women.
IL-6 but also are less sensitive to endogenous signals (glucocorticoids) responsible for curtailing inflammatory responses. This may lead to a more rapid development of atherosclerosis in men than in women. ${ }^{1}$

Although speculative, one possible explanation for observed sex differences in lipopolysaccharide stimulated cytokine release and in glucocorticoid sensitivity may relate to different concentrations of gonadal steroids. The female immune system is influenced by both oestrogens and progesterones. Oestrogens may dose dependently affect lipopolysaccharide associated changes in immune responses of macrophages. ${ }^{1341}$ Compared with men, women in the luteal phase of the menstrual cycle had diminished monocyte release of TNF $\alpha$ and IL- 6 with lipopolysaccharide. ${ }^{37}$ In that study, these effects correlated with the concentration of oestradiol in plasma. The male immune system, on the other hand, is under the control of testosterone and other androgens, which apparently do not affect macrophage function. ${ }^{42-45}$

Despite increasing knowledge of the pathways through which gonadal steroids and glucocorticoids influence immunological target tissues, it remains unknown how these steroids interact at peripheral inflammatory sites. The activated oestrogen receptor has been shown to inhibit the transcription factors nuclear factor $\mathrm{\kappa B}$ and activator protein $1 .{ }^{46}$ Progesterone, because of its structural similarities with

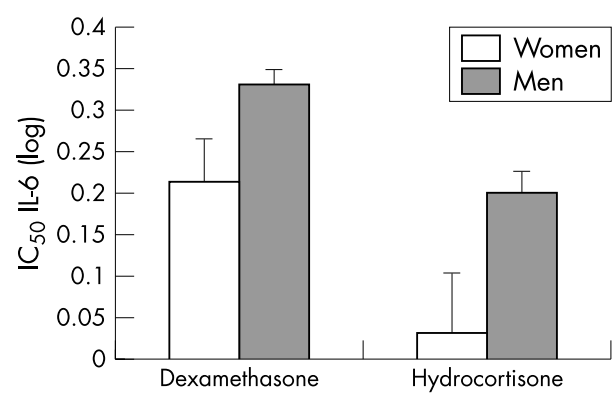

Figure 4 Glucocorticoid (dexamethasone or hydrocortisone) sensitivity of lipopolysaccharide stimulated release of IL-6 in samples from men and women. Samples from men required relatively more dexamethasone $(p=0.033)$ and hydrocortisone $(p=0.029)$ to suppress lipopolysaccharide stimulated IL-6 release than did samples from women. 
the glucocorticoids receptor, has been reported to increase cytosolic mRNA concentrations of the nuclear factor $\kappa B$ inhibitor. ${ }^{48}$ By these mechanisms, both female gonadal steroids seem to exert anti-inflammatory effects.

Da Silva has proposed several mechanisms by which gonadal steroids may modulate the sensitivity of target tissues towards glucocorticoids. ${ }^{49}$ In animal and cell culture studies, $17 \beta$ oestradiol has been show to decrease the expression of the glucocorticoid receptor and thereby to decrease glucocorticoid sensitivity. ${ }^{50}$ Furthermore, expression of heat shock proteins 70 and 90, which are essential in keeping the glucocorticoid receptor in the cytoplasm in an inactive state (although it can be ligand activated), are modulated by female gonadal steroids. ${ }^{51} 52$

Several limitations of our study require consideration. Firstly, our investigation focused on a working population and, thus, may not be generalisable to clinical populations and to people with overt atherosclerotic disease in particular. Secondly, we can only speculate as to whether the observed differences between men and women are clinically relevant. Thirdly, as we did not assess sex steroids, possible explanations for the observed sex differences in cytokine release and glucocorticoid sensitivity are not unequivocally attributable to hormonal issues. Fourthly, we compared very different group sizes of men and women potentially resulting in different variances of mean values of variables of interest. While Levene's test showed that variances of uninhibited lipopolysaccharide stimulation of TNF $\alpha$ and IL- 6 and of the four $\mathrm{IC}_{50}$ estimates were equal, three of the 20 computations across the four inhibition curves suggested a violation of this assumption (data not shown). Nonetheless, since we built our argument on sex differences in uninhibited stimulation of proinflammatory cytokines and calculated IC $_{50}$ values, we feel that this caveat did not invalidate our findings.

In summary, our data show that monocytes from middle aged men have reduced responsiveness to glucocorticoids even when established cardiovascular risk factors are controlled for. This finding of reduced glucocorticoid sensitivity in men implies relatively sustained cytokine production once monocytes have encountered stressful stimuli (such as lipopolysaccharide). Such a mechanism may be one possible biological pathway linking sex to progression of atherosclerotic disease and increased coronary risk in men.

\section{ACKNOWLEDGEMENTS}

This work was supported by grants from the EADS GmbH, Werk Augsburg, Germany, and from the Swiss Federal Institute of Technology.

\section{Authors' affiliations \\ P H Wirtz, Institute of Clinical Psychology II, University of Zurich, Zurich, Switzerland \\ R von Känel, Division of Psychosomatic Medicine, Department of Internal Medicine, University Hospital, Barne, Switzerland \\ N Rohleder, Institute of Biopsychology, Technical University, Dresden, Germany \\ J E Fischer, Institute for Behavioural Sciences, Swiss Federal Institute of Technology, Zurich, Switzerland}

\section{REFERENCES}

1 Rossouw JE. Hormones, genetic factors, and gender differences in cardiovascular disease. Cardiovasc Res 2002;53:550-7.

2 Schwertz DW, Penckofer S. Sex differences and the effects of sex hormones on hemostasis and vascular reactivity. Heart Lung 2001;30:401-28.

3 Mendelsohn ME, Karas RH. The protective effects of estrogen on the cardiovascular system. N Engl J Med 1999;340:1801-11.

4 Reckelhoff JF. Gender differences in the regulation of blood pressure. Hypertension 2001;37:1199-208.

5 Kirkland RT, Keenan BS, Probstfield JL, et al. Decrease in plasma high-density lipoprotein cholesterol levels at puberty in boys with delayed adolescence: correlation with plasma testosterone levels. JAMA 1987;257:502-7.
6 Ross R. Atherosclerosis: an inflammatory disease. N Engl J Med 1999;340:115-26

7 Plutzky J. Inflammatory pathways in atherosclerosis and acute coronary syndromes. Am J Cardiol 2001;88:10K-5K.

8 Pena LR, Hill DB, McClain CJ. Treatment with glutathione precursor decreases cytokine activity. JPEN J Parenter Enteral Nutr 1999;23:1-6.

9 Van der Wal AC, Das PK, Tigges AJ, et al. Adhesion molecules on the endothelium and mononuclear cells in human atherosclerotic lesions. Am J Pathol 1992;141:1427-33.

10 Ridker PM, Rifai N, Pfeffer $M$, et al. Elevation of tumor necrosis factor-alpha and increased risk of recurrent coronary events after myocardial infarction. Circulation 2000; 101:2149-53.

11 Ridker PM, Rifai N, Stampfer MJ, et al. Plasma concentration of interleukin-6 and the risk of future myocardial infarction among apparently healthy men. Circulation 2000;101:1767-72.

12 Koukkunen H, Penttila K, Kemppainen A, et al. C-reactive protein, fibrinogen, interleukin- 6 and tumour necrosis factor-alpha in the prognostic classification of unstable angina pectoris. Ann Med 2001;33:37-47.

13 Miller L, Hunt JS. Sex steroid hormones and macrophage function. Life Sci 1996;59:1-14.

14 Rohleder N, Schommer NC, Hellhammer DH, et al. Sex differences in glucocorticoid sensitivity of proinflammatory cytokine production after psychosocial stress. Psychosom Med 2001;63:966-72.

15 Franchimont $D$, Louis $E$, Dupont $P$, et al. Decreased corticosensitivity in quiescent Crohn's disease: an ex vivo study using whole blood cell cultures. Dig Dis Sci 1999;44:1208-15.

16 Schlaghecke R, Kornely E, Wollenhaupt J, et al. Glucocorticoid receptors in rheumatoid arthritis. Arthritis Rheum 1992;35:740-4.

17 DiBattista JA, Martel-Pelletier J, Antakly T, et al. Reduced expression of glucocorticoid receptor levels in human osteoarthritic chondrocytes: role in the suppression of metalloprotease synthesis. J Clin Endocrinol Metab 1993;76:1128-34.

18 Lane SJ, Lee TH. Mechanisms of corticosteroid resistance in asthmatic patients. Int Arch Allergy Immunol 1997;113:193-5.

19 Spahn JD, Landwehr LP, Nimmagadda S, et al. Effects of glucocorticoids on lymphocyte activation in patients with steroid-sensitive and steroid-resistant asthma. J Allergy Clin Immunol 1996;98:1073-9.

20 Wick G, Hu Y, Schwarz S, et al. Immunoendocrine communication via the hypothalamo-pituitary-adrenal axis in autoimmune diseases. Endocr Rev 1993; 14:539-63.

21 Chrousos GP. The hypothalamic-pituitary-adrenal axis and immune-mediated inflammation. N Engl J Med 1995;332:1351-62.

22 Breuninger LM, Dempsey WL, Uhl J, et al. Hydrocortisone regulation of interleukin-6 protein production by a purified population of human peripheral blood monocytes. Clin Immunol Immunopathol 1993;69:205-14.

23 DeRijk R, Michelson D, Karp B, et al. Exercise and circadian rhythm-induced variations in plasma cortisol differentially regulate interleukin-1 beta (IL-1 beta), IL-6, and tumor necrosis factor-alpha (TNF alpha) production in humans: high sensitivity of TNF alpha and resistance of IL-6. J Clin Endocrinol Metab 1997;82:2182-91.

24 Franchimont $\mathbf{D}$, Martens $\mathrm{H}$, Hagelstein $\mathrm{MJ}$, et al. Tumor necrosis factor alpha decreases, and interleukin-10 increases, the sensitivity of human monocytes to dexamethasone: potential regulation of the glucocorticoid receptor. J Clin Endocrinol Metab 1999;84:2834-9.

25 Ebrecht M, Buske-Kirschbaum A, Hellhammer D, et al. Tissue specificity of glucocorticoid sensitivity in healthy adults. J Clin Endocrinol Metab 2000;85:3733-9.

26 Schnorpfeil P. Allostatic load, vital exhaustion and job characteristics in employees of the manufacturing industry. Zurich: University of Zurich, 2001.

27 Michael YL, Colditz GA, Coakley E, et al. Health behaviors, social networks, and healthy aging: cross-sectional evidence from the nurses' health study. Qual Life Res 1999;8:711-22.

28 Jonsson D, Rosengren A, Dotevall A, et al. Job control, job demands and social support at work in relation to cardiovascular risk factors in MONICA 1995, Goteborg. J Cardiovasc Risk 1999:6:379-85

29 Seeman TE, Singer BH, Rowe JW, et al. Price of adaptation: allostatic load and its health consequences. MacArthur studies of successful aging. Arch Intern Med 1997; 157:2259-68.

30 Wright SD, Ramos RA, Tobias PS, et al. CD14, a receptor for complexes of lipopolysaccharide (LPS) and LPS binding protein. Science 1990;249:1431-3.

31 Berczi I. Neurohormonal host defense in endotoxin shock. Ann N Y Acad Sci 1998;840:787-802.

32 De Groote D, Zangerle PF, Gevaert $Y$, et al. Direct stimulation of cytokines (IL-1 beta, TNF-alpha, IL-6, IL-2, IFN-gamma and GM-CSF) in whole blood. I. Comparison with isolated PBMC stimulation. Cytokine 1992;4:239-48.

33 De Groote D, Gevaert Y, Lopez M, et al. Novel method for the measurement of cytokine production by a one-stage procedure. J Immunol Methods 1993;163:259-67.

34 Wiinberg N, Hoegholm A, Christensen HR, et al. 24-h ambulatory blood pressure in 352 normal Danish subjects, related to age and gender. Am J Hypertens 1995:8:978-86.

35 Khoury S, Yarows SA, O'Brien TK, et al. Ambulatory blood pressure monitoring in a nonacademic setting: effects of age and sex. Am J Hypertens 1992;5:616-23.

36 Asai K, Hiki N, Mimura Y, et al. Gender differences in cytokine secretion by human peripheral blood mononuclear cells: role of estrogen in modulating LPS-induced cytokine secretion in an ex vivo septic model. Shock $2001 ; 16: 340-3$.

37 Schwarz E, Schafer C, Bode JC, et al. Influence of the menstrual cycle on the LPS-induced cytokine response of monocytes. Cytokine 2000;12:413-6. 
38 Franchimont $D$, Louis $E$, Dewe W, et al. Effects of dexamethasone on the profile of cytokine secretion in human whole blood cell cultures. Regul Pept 1998;73:59-65.

39 Daun JM, Ball RW, Cannon JG. Glucocorticoid sensitivity of interleukin-1 agonist and antagonist secretion: the effects of age and gender. Am J Physiol Regul Integr Comp Physiol 2000;278:R855-62.

40 Elkind MS, Cheng J, Boden-Albala B, et al. Tumor necrosis factor receptor levels are associated with carotid atherosclerosis. Stroke 2002;33:31-7

41 Chao TC, Chao HH, Chen MF, et al. Female sex hormones modulate the function of LPS-treated macrophages. Am J Reprod Immunol 2000;44:310-8.

42 Li ZG, Danis VA, Brooks PM. Effect of gonadal steroids on the production of IL-1 and IL- 6 by blood mononuclear cells in vitro. Clin Exp Rheumatol 1993; 11:157-62.

43 Flynn A. Stimulation of interleukin-1 production from placental monocytes. Lymphokine Res 1984;3:1-5.

44 Maziere C, Auclair M, Ronveaux MF, et al. Estrogens inhibit copper and cellmediated modification of low density lipoprotein. Atherosclerosis 1991:89:175-82.

45 Baranao RI, Tenenbaum A, Rumi LS. Effects of sexual steroid hormones on the functionality of murine peritoneal macrophages. Steroids 1991;56:481-5.
46 Ruh MF, Bi Y, D'Alonzo $R$, et al. Effect of estrogens on IL-1 beta promoter activity. J Steroid Biochem Mol Biol 1998;66:203-10.

47 Ray P, Ghosh SK, Zhang DH, et al. Repression of interleukin-6 gene expression by 17 beta-estradiol: inhibition of the DNA-binding activity of the transcription factors NF-IL6 and NF-kappa B by the estrogen receptor. FEBS Lett 1997:409:79-85.

48 Miller AH, Spencer RL, Pearce BD, et al. Glucocorticoid receptors are differentially expressed in the cells and tissues of the immune system. Cell Immunol 1998;186:45-54.

49 Da Silva JA. Sex hormones and glucocorticoids: interactions with the immune system. Ann N Y Acad Sci 1999;876:102-18.

50 Krishnan AV, Swami S, Feldman D. Estradiol inhibits glucocorticoid receptor expression and induces glucocorticoid resistance in MCF-7 human breast cancer cells. J Steroid Biochem Mol Biol 2001:77:29-37.

51 Ramachandran C, Catelli MG, Schneider W, et al. Estrogenic regulation of uterine 90-kilodalton heat shock protein. Endocrinology 1988;123:956-61.

52 Komatsu T, Konishi I, Fukomoto M, et al. Messenger ribonucleic acid expression of heat shock proteins HSP70 and HSP90 in human endometrium and myometrium during the menstrual cycle. J Clin Endocrinol Metab 1997:82:1385-9.

\section{IMAGES IN CARDIOLOGY}

\section{Unstable angina in a patient with single coronary artery}

A

58 year old woman with hypertension, hypercholesterolaemia, and family history of coronary heart disease presented with a five year history of exertional chest discomfort, relieved by rest and nitrate administration.

Coronary angiography demonstrated a single left coronary ostium (aortography confirmed absence of right coronary artery), left circumflex artery was dominant, and the right coronary artery arose from an unusual location, just after the first septal branch of the left anterior descending artery (LAD), passing anteriorly to the pulmonary trunk and crossing to the right side of the heart. According to the Lipton classification, this anomaly could be classified as LII-A (panels A and B).

Interestingly, although the coronary tree was generally free of atheroma, a significant stenosis was demonstrated within the abnormal artery (panels A and B, arrowheads). This was wired and stented directly with a $2.75 \times 8 \mathrm{~mm}$ stent, but resulted in some impingement in the main LAD, perhaps due to "snow-plough" (panel C, arrowhead). After preinflation of both branches, a "kissing balloon" inflation was performed in the LAD and in the aberrant vessel, with good angiographic final appearance (panel D).

Coronary artery anomalies occurs in 0.64$5.6 \%$ of patients undergoing coronary angiography. They have been associated with increased risk of sudden death, mainly when an aberrant branch is compressed between the great vessels. In our case the unusual anatomy may have played a role in determining the location of this single lesion, as an almost right angle takeoff is associated with decreased mechanical shear stress, and could predispose to atheroma formation.

I Porto
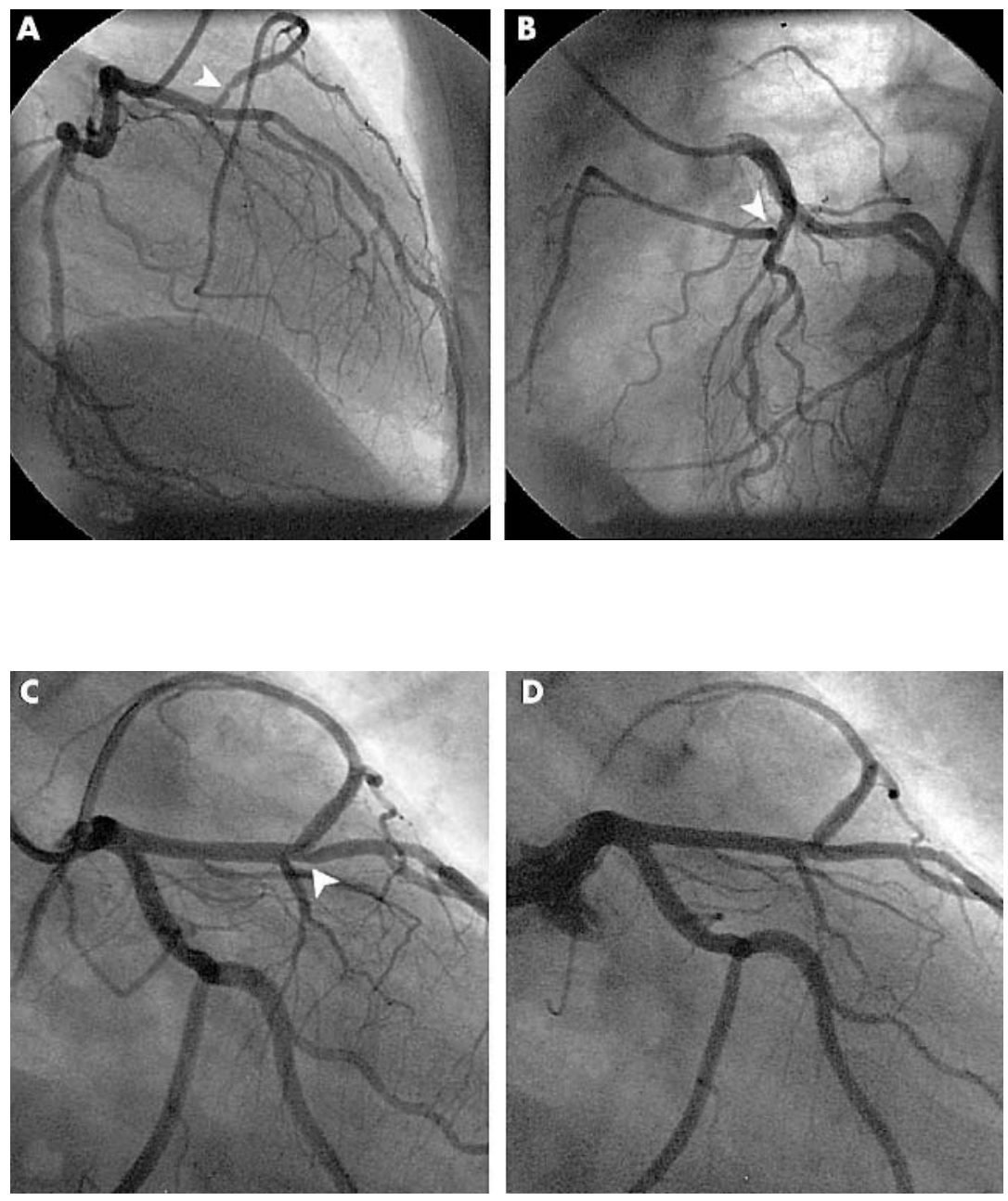